\title{
Rail temperature variation under heavy haul operations
}

\author{
Chris Bosomworth $^{1,2}$ (1) Maksym Spiryagin ${ }^{1,2} \cdot$ Sanath Alahakoon $^{1,2} \cdot$ \\ Colin Cole $^{1,2} \cdot$ Ben Sneath $^{1} \cdot$ Bruce Makin $^{3}$
}

Received: 8 February 2021/Revised: 22 December 2021 / Accepted: 28 December 2021 / Published online: 11 February 2022

(C) The Author(s) 2022

\begin{abstract}
There currently does not exist in industry a reliable method for the detection of rail foot flaws. Like their head-based counterparts, foot flaws result in broken rail with potentially catastrophic consequences. A proposed area of research for the detection of these flaws is thermography, a non-contact method of measuring and analysing infrared emissions from an object under test. In industry, active excitation thermography is the most common, requiring an excitation source. This paper will present a temperature measurement system and a method of transient temperature extraction from the running rails for the effects of a passing train to evaluate heat transfer in the practical rail environment. The outcomes of these results will provide future direction in the development of a rail heat transfer model and determine if train passage provides enough active excitation for a thermography-based detection technique.
\end{abstract}

Keywords Rail heat transfer - Rail foot flaws · Field temperature measurement - Transient temperature extraction

Chris Bosomworth

c.bosomworth@cqu.edu.au

1 Centre for Railway Engineering, Central Queensland University, Rockhampton 4702, Australia

2 Australasian Centre for Rail Innovation, Canberra 2601, Australia

3 ARC Infrastructure, Perth 6105, Australia

\section{Introduction}

Rail flaws can delay services and cause derailments, resulting in negative impacts on an operator's ability to meet haulage targets and run an efficient organisation. Rail flaw detection techniques today focus on rail head flaws through the use of coupled ultrasound and eddy current systems [1] and are limited to what can be detected from a head-based signal injection. However, rail foot flaws do occur and can result in broken rails.

There are currently limited rail foot flaw detection techniques. Head-induced ultrasound can detect corrosion in the foot directly below the web but is severely limited near the edge of the foot where transverse cracks are most likely to occur. This area of the foot presents several physical barriers for contact-based detection techniques, including ballast and rail fasteners, hence a non-contact technique is required.

Over the 11 year period from 1992 to 2002 the FRA identified that rail foot flaws were the fourth highest occurring flaw type accounting for $4.6 \%$ of the total defects on track with a damage bill exceeding \$US49 million [2]. Although the statistics are over 15 years old the lack of development during this time on new detection technologies indicates that the occurrence of rail foot flaws has likely not reduced. In Australia heavy haul rail operators still struggle with rail foot flaw detection and are the primary funding source for research into the problem presented here in this paper. There have been at least two significant derailments in Australia attributed to foot flaws $[3,4]$.

Thermography is a non-contact technique commonly used in nondestructive testing (NDT). It generally requires an active excitation heating effect on an object and measures the infrared response during heating and cooling to 
detect changes in thermal resistance. These changes in thermal resistance present themselves in the imagery as hotspots and may be indicative of a flaw at that point.

In the context of rail foot flaw detection, if the passage of rolling stock can function as an active excitation technique and generate enough heat flux in the foot, this may result in a thermal disturbance around a crack that may be measurable. There are two key sources of train active excitation. The first is generated by wheel/rail surface contact conditions typically from high slip in the contact causing a heating effect in the surface of the rail [5]. The other source of heat transfer originates from wheel/rail conduction. The warm wheels of the train conduct to the cool rail [6]. There are a wide variety of surface temperatures generated due to track topography and train driving strategy and this will influence the rail heat transfer across a rail network [7].

This paper presents an experimental setup and results for measuring rail heat transfer from head to foot, in an operational rail network as a step to informing the future development of a rail heat transfer model and furthermore a Thermography based technique for rail foot flaw detection. These rail temperature measurements will also provide a location indicator on where a thermography based technique may be expected to work effectively.

It details typical heavy haul running scenarios and rationalises the selection of site locations for measurement. For site locations with curves, it attempts to establish a relationship between high and low rail heat transfer for varying radii and locomotive traction conditions. Tangent locations shall explore traction only. It concludes with an analysis of the temperature changes generated in the foot of the rail by the passage of trains.

\section{Methodology}

To measure rail heat transfer vertically through the rail in a practical operational scenario, there are several factors to consider. There are countless variations in curvature and gradient that can be measured, however, what are the combinations that should be measured? How can sensors be securely fitted to the rail, ensuring their survivability, optimising thermal conductivity and providing electrical isolation between the two rails being measured? Lastly, given the complications in obtaining live track access, how can we minimise equipment failure and data integrity?

This methodology describes the experimental setup for a rail temperature measurement device that is autonomous, high precision per channel, fast to install and remove and low cost. The emphasis of the device is taking time synchronised measurement at the rail head, web and foot to explore heat transfer due to the active excitation of passing trains. These devices will be installed across five locations of differing tractive, braking and curvature. The analysis section presents a method for extracting the transient temperature for each passing train given the field limitations and challenges of the installed units.

\subsection{Experimental setup}

The key requirements and their rationales describing the limitation and challenges of the experimental setup for measuring rail temperature given the objectives described in the methodology introduction are shown in Table 1.

\subsubsection{Sensors}

The sensing requirements in Sect. 2.1 direct the choice, design and development of the measurement solution. The first step is to determine the most appropriate type of sensor. As the head, web and foot must be measured on each rail for up to six different site locations, a minimum of 36 temperature sensors are required. To reduce the opportunity for physical contact with the train, the logging box must be located at least $2-3 \mathrm{~m}$ from the nearest rail. In this case we could expect a $4 \mathrm{~m}$ cable run to the farthest rail. Taking these considerations into account, Table 2 provides a brief evaluation of different temperature sensor types and the benefits and drawbacks. It was deduced that an IC (integrated circuit) sensor type would be the most appropriate for our application and the LM35 temperature sensor was selected [8]. The LM35 Precision Centigrade temperature sensor is an IC device with an output voltage linearly proportional to the current temperature with a nonlinearity of approximately $\pm 0.25^{\circ} \mathrm{C}$. It works over an operating range of -55 to $150{ }^{\circ} \mathrm{C}$ and has low self-heating of $0.08{ }^{\circ} \mathrm{C}$ in still air. The sensor is also very cost effective for the quantities required in the proposed project.

When accessing a live track environment, it is essential that the installation be as efficient as possible, so as to keep intrusion and delays for operational trains to a minimum [9]. To meet the time constraints for installation and removal, an alternative solution to using traditional adhesives is required. The first rationale behind this decision was that the use of fast acting adhesive such as 90-s epoxy adhesive would allow for quick installation but may ultimately result in the destruction of the device when removing. In addition to this, Epoxy adhesives typically have a low thermal conductivity of $0.22 \mathrm{~W} / \mathrm{mK}$ that would reduce the responsiveness of the temperature sensor. The resulting design choice is to develop a magnetically attached temperature sensor that could be both installed and removed very quickly [10]. The magnets used were scavenged from broken hard disk drives. These are neodymium permanent magnets with pull strengths varying 
Table 1 Table of requirements and their rationales

\begin{tabular}{ll}
\hline Requirement & Rationale \\
\hline $\begin{array}{l}\text { Capable of measuring local time synchronised rail head, web and foot } \\
\text { temperature across both rails at a rate no less than once per second }\end{array}$ & $\begin{array}{c}\text { Limited to low sample rate due to rate of conduction from head to } \\
\text { foot } \\
\text { Able to be configured, attached to the rail and removed at the conclusion ofLong-time windows for installation are often difficult to obtain } \\
\text { the test in the shortest time possible to reduce intrusion on normal rail } \\
\text { from train control on busy rail corridors }\end{array}$ \\
$\begin{array}{l}\text { Have sufficient battery to run unattended for at least } 48 \mathrm{~h} \\
\begin{array}{l}\text { Able to survive environmental conditions where ambient and rail } \\
\text { temperatures may exceed } 40{ }^{\circ} \mathrm{C} \text { and } 70{ }^{\circ} \mathrm{C} \text {, respectively }\end{array}\end{array}$ & $\begin{array}{c}\text { Test to be conducted in summer in Australia and this is typical } \\
\text { operating temperatures for this season }\end{array}$ \\
$\begin{array}{l}\text { High precision }<0.1{ }^{\circ} \mathrm{C} \text { (high accuracy not needed as sensors will be } \\
\text { synchronised) }\end{array}$ & $\begin{array}{c}\text { Ability to achieve similar temperature measurement precision as } \\
\text { Infrared camera }\left(0.06{ }^{\circ} \mathrm{C}\right)\end{array}$ \\
$\begin{array}{l}\text { Up to six different site locations to be measured in parallel } \\
\text { Low cost solution with maximum build price below } \$ 1000\end{array}$ & $\begin{array}{l}\text { Directed according to site locations as described later in the paper } \\
\text { Budget constraint for project }\end{array}$ \\
\hline
\end{tabular}

Table 2 Comparison of different temperature sensors

\begin{tabular}{lllll}
\hline Criteria & $\begin{array}{l}\text { Resistance temperature } \\
\text { detector }\end{array}$ & Thermistor & Thermocouple & IC sensor \\
\hline Temperature range $\left({ }^{\circ} \mathrm{C}\right)$ & -250 to 750 & -100 to 500 & -267 to 2316 & -55 to 200 \\
Accuracy & High & Conditional on calibration & Moderate & Moderate \\
Linearity & Moderate & Nonlinear & Moderate & High \\
Sensitivity & Moderate-poor & High & Poor & Moderate \\
Circuitry & Complex & Conditional & Complex & Simple \\
\hline
\end{tabular}

from 2 to more than $20 \mathrm{~kg}$. The scavenged versions have a pull strength over $10 \mathrm{~kg}$, which is sufficient to hold the lightweight sensor in place on the rail for the duration of the test regime. The high magnetic field produced by these magnets do not influence the performance characteristics of the temperature sensor.

Given the low cost of the LM35 temperature sensor, and for measurement redundancy, each location on the rail would have two temperature sensors installed. A diagram of the resultant transducer is shown in Fig. 1. The two temperature sensors are located at either end of the magnet and glued in place on a metal plate. The metal plate and electronics is then housed in a backing shell and potted with epoxy. The protective backing shell is 3D printed in polylactic acid (PLA) with a wall thickness of $3 \mathrm{~mm}$ and honeycomb internal structure, to insulate from any external radiation or convective influences on the LM35 sensors. PLA is a reasonable insulator with a thermal conductivity of $0.13 \mathrm{~W} / \mathrm{mK}$. Any potting compound covering the LM35 temperature sensors is ground off once the epoxy has completely gone off to ensure optimal sensor/rail contact.

Covering the entirety of the sensor to rail contact surface is a thermally conductive and electrically insulating pad with dimension of $75 \mathrm{~mm} \times 22 \mathrm{~mm} \times 1.15 \mathrm{~mm}(L \times W \times D)$. The thermal conductivity of the pad is $1.7 \mathrm{~W} / \mathrm{mK}$. It is required to ensure that the two sets of temperature sensors that connect to either rail remain completely electrically insulated from the rail samples. Any electrical crosstalk between rails interferes with electrical signalling systems and may detrimentally impact the operational network.

The final design decision for the transducer shells was to determine the installation arrangement. Two choices were considered, mounting the three shells vertically above each other on the rail or stringing them out along the rail. Intuitively, arranging the shells vertically would seem the best method, particularly for the problem of measuring heat transfer to the foot, however, this arrangement has several drawbacks. From a physical perspective, looping the cable between each shell exposes itself to potential contact with a passing train. The second issue is the effect vertical placement has in the region on convection and radiation of the rail. It essentially acts as a partial insulator in that region. Stringing the shells out along the rail mitigates the convection and radiation effect and, if tensioned correctively, limits loose cable in the rail environment. The key drawback to the stringing method is that there is not a direct conduction path. This is mitigated by setting the shell placements on the rail at mid-span locations between consecutive sleepers as shown in Fig. 2. 


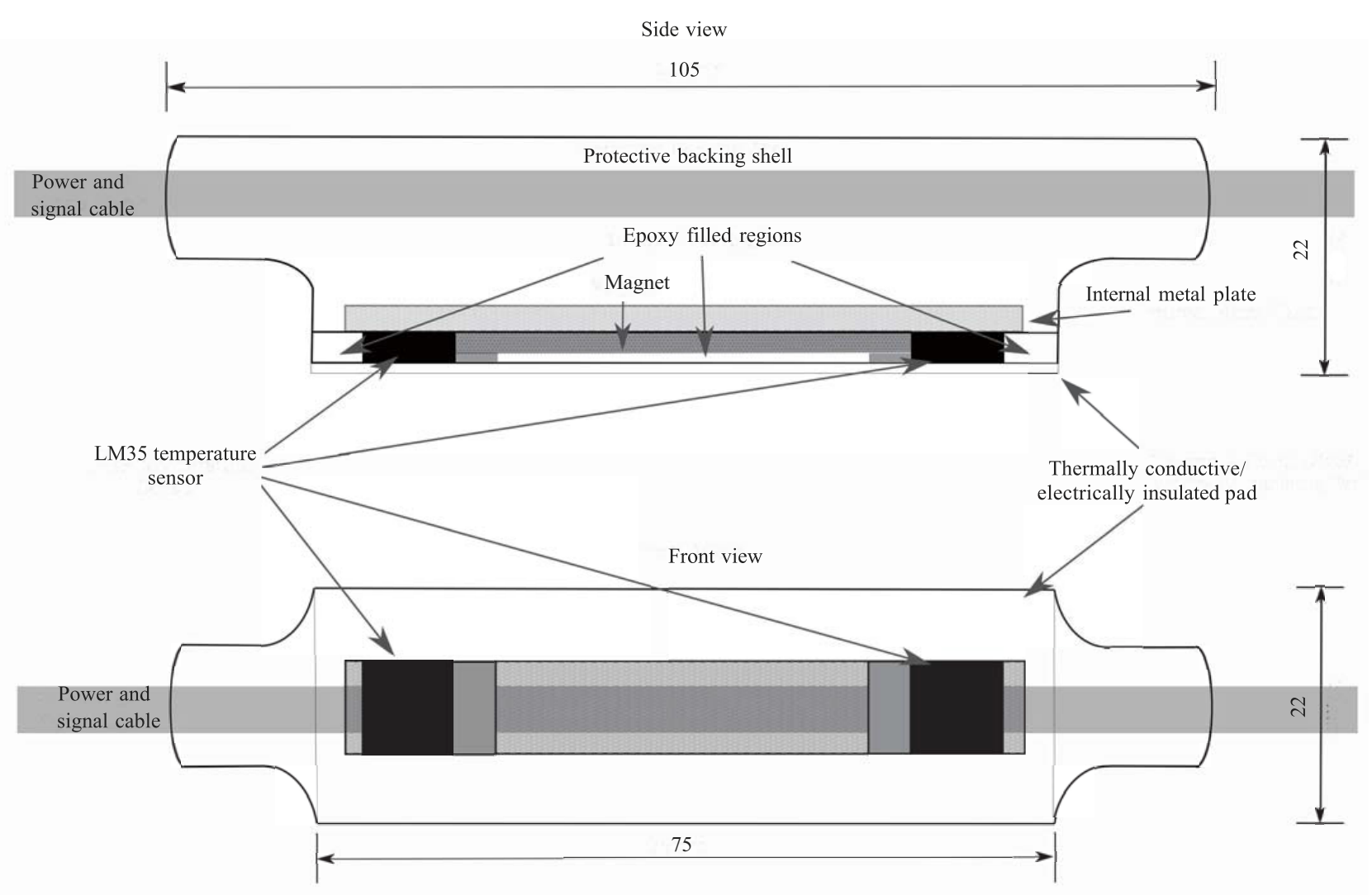

Fig. 1 Transducer design for rail temperature measurement (unit: mm)

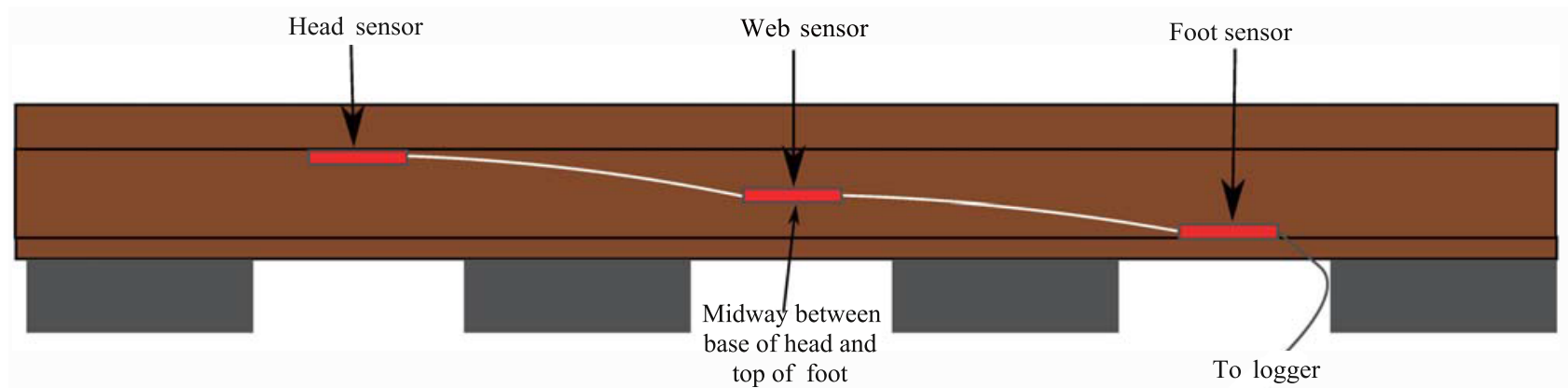

Fig. 2 Mid-span stringing of the sensors on the rail

For the mid-span sleeper installation assumption to hold it requires some consideration on the field installation site to ensure it is in a location that does not appear to undergo any significantly high transient effects. Such effects may include the lateral oscillatory motion observed on curve transitions and any vertical track movement due to soft sub-grade. Track recording data and local inspection of the rail head wear at the installation site will help determine a consistent region for installation of the temperature sensors. This is then expected to provide a consistent local energy input into the top of rail for the span that the sensors cover.

\subsubsection{Data logger}

A data logger for acquiring the temperature measurements and writing these results to permanent storage is required. Due to the short recording duration of the test would suggest a battery only power solution is enough in this case. There has been a large increase in the availability of 
low power loggers due to the popularity of the Raspberry $\mathrm{Pi}$ and Arduino platforms, particularly those based on ARM Cortex cores. Previous data acquisition projects at the Centre for Railway Engineering have utilised the Adafruit Feather-M0 Adalogger [11], an ARM Cortex-M0 system utilising the Arduino electronic form factor. However, it does not share the same Arduino physical form factor.

The base-line power consumption of the Adalogger without any sleep mode functions is approximately $10 \mathrm{~mA}$ and, with the SD card enabled and writing frequently, this increases to around $20-30 \mathrm{~mA}$. The device requires a 5 VDC source and has an input voltage range of 3.75 to 6 VDC. The worst-case logging time is defined as $72 \mathrm{~h}$; therefore the energy requirement for a single device is $1440 \mathrm{mAh}$. As described later in the paper, two loggers are incorporated into the final design, resulting in an approximate consumption of $3000 \mathrm{mAh}$. Considering the capacity of standard alkaline batteries, namely AAA (1000 mAh), AA (2500 $\mathrm{mAh})$ and $\mathrm{C}(8000 \mathrm{mAh})$ all with nominal voltages of $1.5 \mathrm{VDC}$, the best power choice was $4 \mathrm{C}$-cell batteries in series providing a nominal 6 VDC input. The life expectancy of the system can be increased by orders of magnitude through the introduction of sleep/standby functionality and this will be the topic of future papers.

The Arduino default data acquisition resolution is 10-bit for compatibility across the different microprocessor variations. This was changed to 12-bit and the ADC (analog-todigital converter) pre-scaler for the peripheral clock changed from its default DIV512 to DIV8.

To improve the resolution of the temperature measurement, an investigation into whether the ADC and temperature sensors supported oversampling was performed. Oversampling is a method whereby a significantly higher sample rate than what is required is sampled and then averaged to improve the effective resolution of the ADC. The Adalogger was programmed to write data to the serial port for a single analogue input channel at a rate of 115,200 bits per second, with a per byte framing protocol configuration of 8 data bits, no parity and1 stop bit, for the attached temperature sensors. A histogram of a sample set for one input channel of recorded data and its normal distribution is shown in Fig. 3. Although the recorded data is not a perfect fit, it does demonstrate sufficient white noise approximation that oversampling will increase the resolution of the acquired temperature sensors. The data rate with an oversampling average calculated resulted in an acquisition data rate of approximately $10 \mathrm{KS} / \mathrm{s}$ (kilo samples per second). With a best case $\sqrt{ } N$ resolution improvement, this would equate to a 6-bit increase. However, this is unlikely given the white noise approximation and the small staircase artefact and right skew.

To add a level of data redundancy to the test, two loggers have been integrated into the logger system. As described in the sensor section, each rail sensor location has two temperature sensors fitted in its backing shell. The temperature sensors at each rail location are then spliced across the two loggers. The wiring diagram for the system is shown in Fig. 4 and indicates the splicing arrangement. This guarantees that, if one Adalogger fails for any reason, the other logger still acquires temperature measurements for both rails. In the case where both loggers execute as expected, it provides comparative data at each location or alternatively the second channel can be ignored.

The two "strings" comprised of six temperature sensors each are labelled A and $\mathrm{B}$. The sensor notation used is $x \mathrm{~T} n$, where $x$ is the temperature string type (A/B) and $n$ is the sensor number from 1 to 6 . The sensors are labelled in order from foot to head, i.e. foot $(1,2)$, web $(3,4)$ and head $(5,6)$. When referring to a specific sensor throughout the

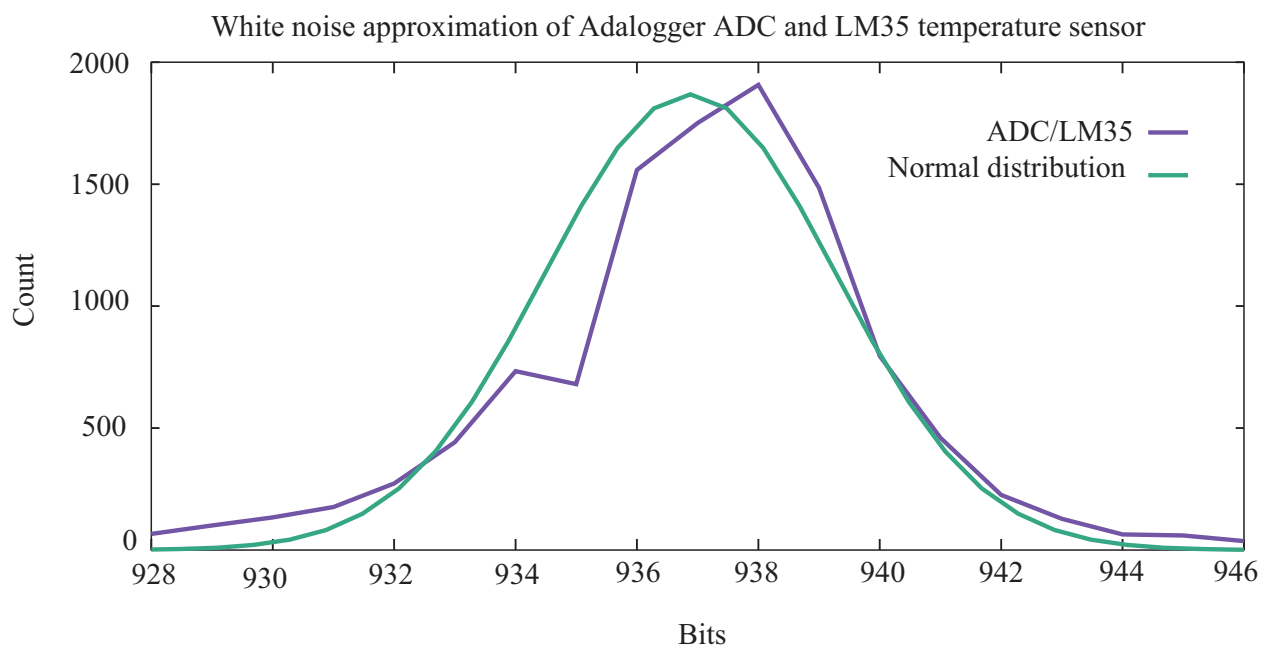

Fig. 3 Evaluating the effectiveness of oversampling using the Adalogger ADC and LM35 temperature sensor 


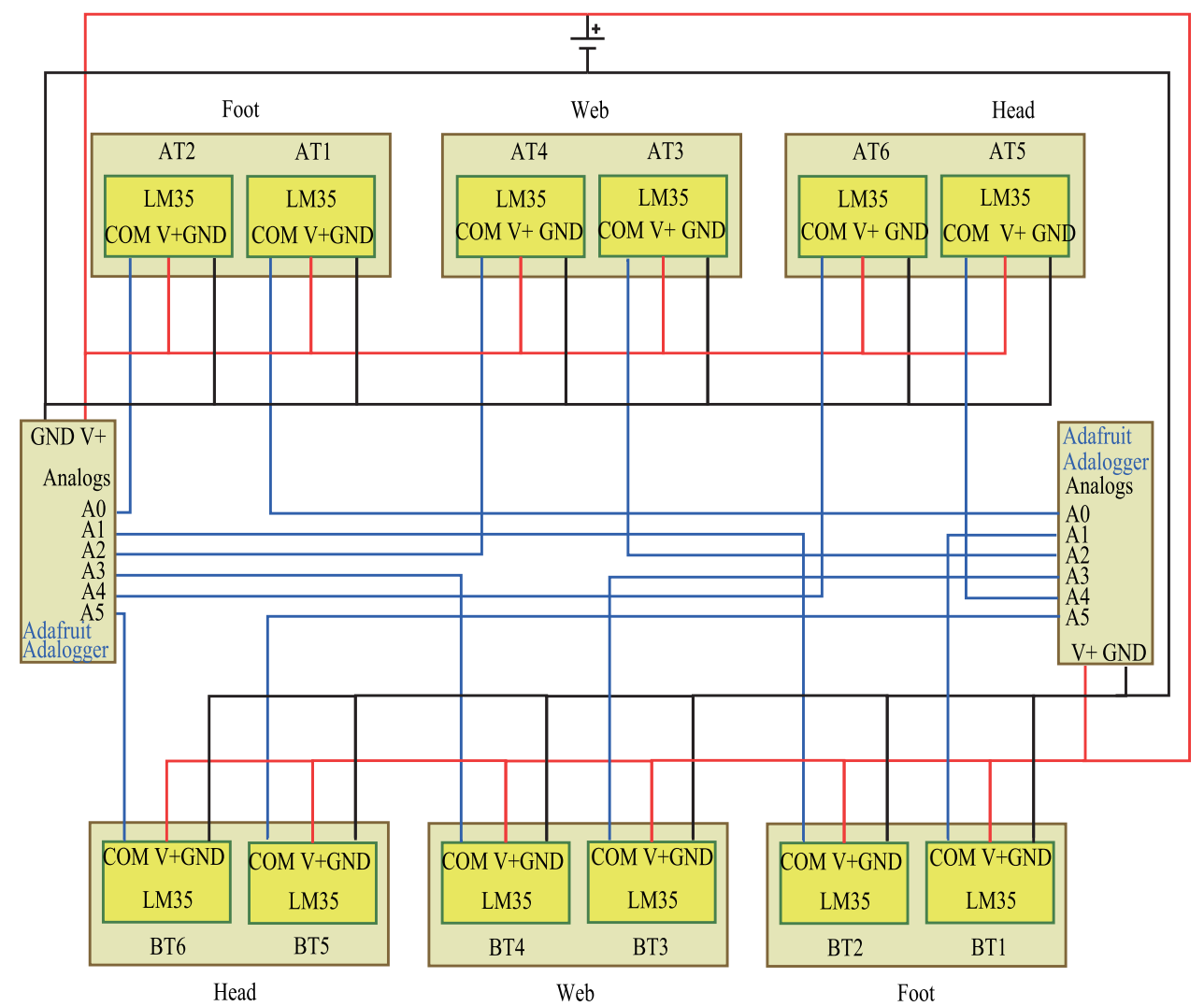

Fig. 4 Wiring diagram for temperature measurement data acquisition system

remainder of the paper, the description will include an abbreviation of its position, head (H), web (W) and foot (F).

\subsection{Installation}

Given the rationales laid out by this paper, the installation of the sensor and logging box are straightforward. To improve the thermal conductivity from the rail for the sensor installation, it is cleaned with a cordless drill and wire brush at all six mounting locations. A small amount of ballast is removed from underneath both rails to run the sensor cable from the far rail with the logger box placed at least $2 \mathrm{~m}$ from the nearest rail to avoid any dragging equipment that may be present on rolling stock. The entire installation at a track site can be completed under $10 \mathrm{~min}$.

Heavy haul train operations can be broken down into the following categories:

(1) Tangent track-low to moderate traction: this type of running is usually typified by shallow track grades and limited need for either high tractive or dynamic braking efforts.

(2) Tangent track-heavy traction: in the tractive effort (TE) case results in heavy haul trains typically lugging at slow speed up steep grades close to, or at, maximum TE; alternatively in the braking case, either large amounts of dynamic brake (DB) or train brake are applied in a grade descent scenario.

(3) Large curve radius-all traction types: it can be considered a subset of points 1 and 2; large curve radii greater than $800 \mathrm{~m}$ do not typically impact heavy haul train performance.

(4) Tight curve radius-low to moderate traction: like point 1 with the inclusion of potentially high lateral load depending on train speed and curve superelevation.

(5) Tight curve radius- - high traction: like point 2 with the inclusion of increased spin under traction due to the tight curve radius.

While there are undoubtedly thousands of combinations of gradient, curvature and traction, under closer inspection they will fit into one of these five categories.

Based on a train simulation of a loaded iron ore train using driving logs for the target network, five locations were selected as listed in Table 3 . The site numbers are in ascending order of kilometre position according to the track network diagram. As detailed in Table 3, the selected locations cover points 2 through to 5 described above. 
Table 3 Site locations for temperature logger installation

\begin{tabular}{lllll}
\hline Site No. & Curve radius $(\mathrm{m})$ & Traction & Train braking & Lateral \\
\hline 1 & 800 & High & No & High \\
2 & Tangent & High & No & No \\
3 & 800 & Low & No & High \\
4 & 300 & Low & High & High \\
5 & 240 & High & No & High \\
\hline
\end{tabular}

\subsection{Train types}

There are two main types of trains operating on the rail network under test, namely iron ore and fuel. Table 4 defines the key train consist parameters for each train type.

\subsection{Analysis}

Field measurement of transient temperatures due to passing trains will be aggregated in the cyclic 24-h weather pattern. A preferable method for removing the low frequency content would be to have a duplicate short piece of reference rail at each location with a temperature sensor attached, however, this was not possible due to site accessibility and health and safety reasons. Even a short $30 \mathrm{~cm}$ section of AS60 rail would weigh $18 \mathrm{~kg}$. The proposed concept is to create a reference signal that can be subtracted from the measured data, leaving only the temperature transients of the train, resulting in an auto-zeroing of the temperature channel. As we are only looking for a change in temperature, the temperature sensor measurement only requires having a high precision and not accuracy as the low frequency content is removed from the signal. The other benefit of this is that no calibration of the temperature measurement is required as the analysis is not working in the absolute space.

There are a few potential approaches to achieving this:

- A deterministic method using local weather data and an energy equilibrium model using rail material parameters, solar, convection and radiation as described by Kessler and Zhang [12] to calculate the temperature of the rail.
- Synthesising a waveform based on the $24 \mathrm{~h}$ cyclic nature of the weather.

- Low pass filtering to remove the transients, leaving only the cyclic reference waveform.

- High pass filtering to remove the low frequency cyclic component. This varies from the other three approaches in that it implicitly removes the cyclic component.

The first option is quite sensitive to local weather perturbations and, as only one of the five sites was located near a weather station, this method is not being considered at this stage, but it may be considered in the future. Initial experimentation with high and low pass filtering of the waveform have proved problematic and these methods shall be explored in further detail in future work. Therefore, for this paper, the reference signal method adopted is the synthesising of a waveform.

To remove the 24-h cyclic effect from the recorded results requires an arbitrary function. A Fourier series can fit any arbitrary function based on a trigonometric series of the form:

$S_{N}(t)=A_{0}+\sum_{n=1}^{N} A_{n} \sin \left(\frac{2 \pi n t}{P}+\phi_{n}\right)$,

where $A_{0}$ is the constant offset, $N$ is the number of harmonics, $A_{n}$ is the respective harmonic amplitude, $P$ is the period of the fundamental wave and $\phi_{n}$ is the phase shift for the respective harmonic.

For the recorded data it is known that the period of the fundamental frequency is $24 \mathrm{~h}$ or $86,400 \mathrm{~s}$. For the proposed problem the number of harmonics $(N)$ shall be limited to 6. The limitation in harmonics is introduced to manage the number of coefficients to solve for the chosen

Table 4 The two most common train types on the network

\begin{tabular}{lllll}
\hline Train type & Consist & Average length $(\mathrm{m})$ & Average empty mass $(\mathrm{t})$ & Average loaded mass $(\mathrm{t})$ \\
\hline Iron ore & L2W106L2W54 & 1792 & 2925 & 14,025 \\
Fuel & L2W15 to 30 & 453 & 521 & 1940 \\
\hline
\end{tabular}


minimiser. The Fourier series describing the reference signal problem becomes

$\mathrm{Temp}_{\mathrm{ref}}(t)=A_{0}+\sum_{n=1}^{6} A_{n} \sin \left(\frac{2 \pi n t}{86,400}+\phi_{n}\right)$.

That results in a set of 13 coefficients to solve. To find a solution to those coefficients the Levenberg-Marquardt method, or damped least-squares method is used [13]. The coordinates selected for curve fitting are important. Selecting too many points can result in local error being lost in the resultant error calculation, while too few points do not provide enough information for the method to generate a satisfactory fit across the time series domain.

Given the sampling rate and duration, a method of down sampling the signal is needed. The rail operator has provided the approximate train passage times for each site and these regions should be excluded from the coordinate selection. An arbitrary region of $1800 \mathrm{~s}$ either side of the designated passage time has been selected as the exclusion interval. The highlighted blue regions in Fig. 5 are the exclusion region when trains ran over the measurement site. These are visually quite distinctive due to the fast rise in temperature compared to ambient conditions and align with the train run times provided by the operator.

The set of coordinates required must be at least 13 , which is the number of coefficients in our fitting function. With a minimum site run-time duration of approximately $80,000 \mathrm{~s}$ and over $10,000 \mathrm{~s}$ of recorded temperatures excluded due to train passage, a coordinate shall be selected from the set of data every $1000 \mathrm{~s}$. This generates approximately 70 coordinates for the site with the shortest run-time. An example showing the measured data, selected coordinates (black boxes) and fitted function is shown in Fig. 5.

The resultant signal is then expressed as $\operatorname{Temp}_{\text {trans }}(t)=\operatorname{Temp}_{\text {meas }}(t)-\operatorname{Temp}_{\text {ref }}(t)$, where Temp $\mathrm{trans}_{\text {is }}$ is the resultant signal after removing the enviromental reference signal, $\mathrm{Temp}_{\mathrm{ref}}$, from the measured signal Temp meas. An example of the resultant transient is shown in Fig. 6.

Figure 6 shows the temperature variation due to train passage with the cyclic reference removed, and it is now much clearer, allowing for further comparative analysis between the different sites. Like Fig. 5, the train passage regions are highlighted in blue and have a distinctively fast temperature derivative as their active excitation heats the track. Table 5 shows the three different train types that shall be the focus for further analysis. The temperature transients for each train are extracted from the time series temperature data for each site, zeroed against each other and categorised according to their high or low rail position, i.e. which transducer string was attached to which rail.

\section{Results}

An image of the unit installed in the field at site 2 is shown in Fig. 7. The temperature sensor string for the far rail is not visible but runs under the track and is installed in the same orientation as the near rail in the photo. Snippets of temperature data recorded are shown in Figs. 8 and 9. The logged data for all five sites has not been included, however, post-processed results for these are presented later in the paper.

A summary of the units installed and the run-time for which data was collected is shown in Table 6. The tempeature string $\mathrm{A}$ and $\mathrm{B}$ columns indicate whether the respective sensor string was installed on the high or low rail at the site.

Table 5 shows details of the approximate passage times for three different train types for which data was captured. The train passage times provided were stipulated by the

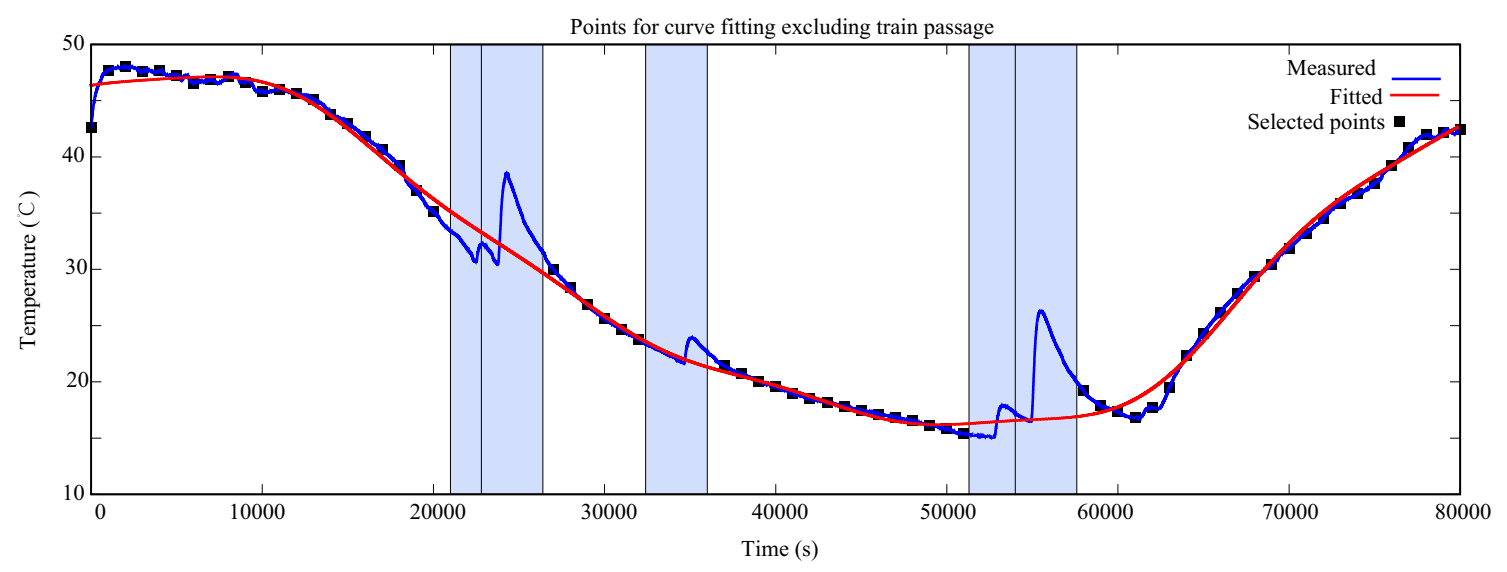

Fig. 5 Selecting points for curve fitting reference 


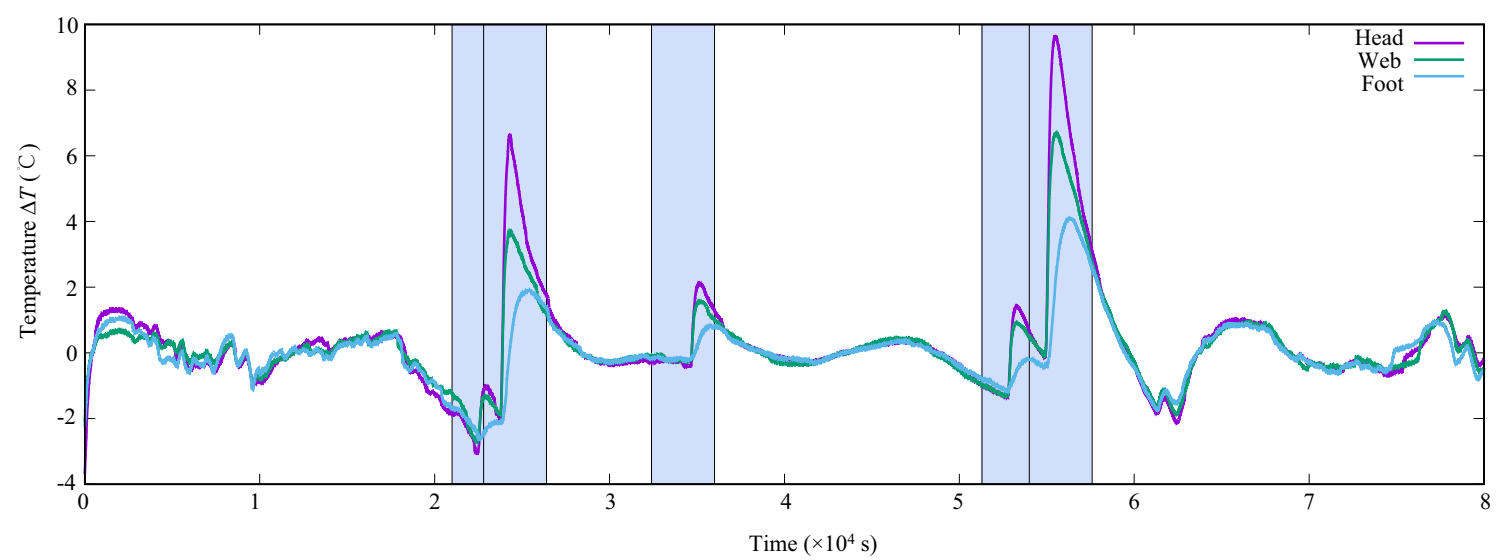

Fig. 6 Resultant transient temperatures with reference removed

Table 5 Approximate train passage times for three different consists

\begin{tabular}{llll}
\hline Site No. & Iron ore loaded & Iron ore empty & Fuel loaded \\
\hline $1(-30 \mathrm{~km})$ & $2017-12-1423: 55$ & $2017-12-1421: 20$ & $2017-12-1501: 10$ \\
2 & $2017-12-1501: 30$ & $2017-12-1420: 30$ & $2017-12-1423: 50$ \\
3 & $2017-12-1501: 30$ & $2017-12-1420: 30$ & $2017-12-1423: 50$ \\
4 & $2017-12-1502: 50$ & $2017-12-1419: 20$ & $2017-12-1422: 30$ \\
5 & $2017-12-1504: 00$ & $2017-12-1418: 50$ & $2017-12-1422: 00$ \\
\hline
\end{tabular}

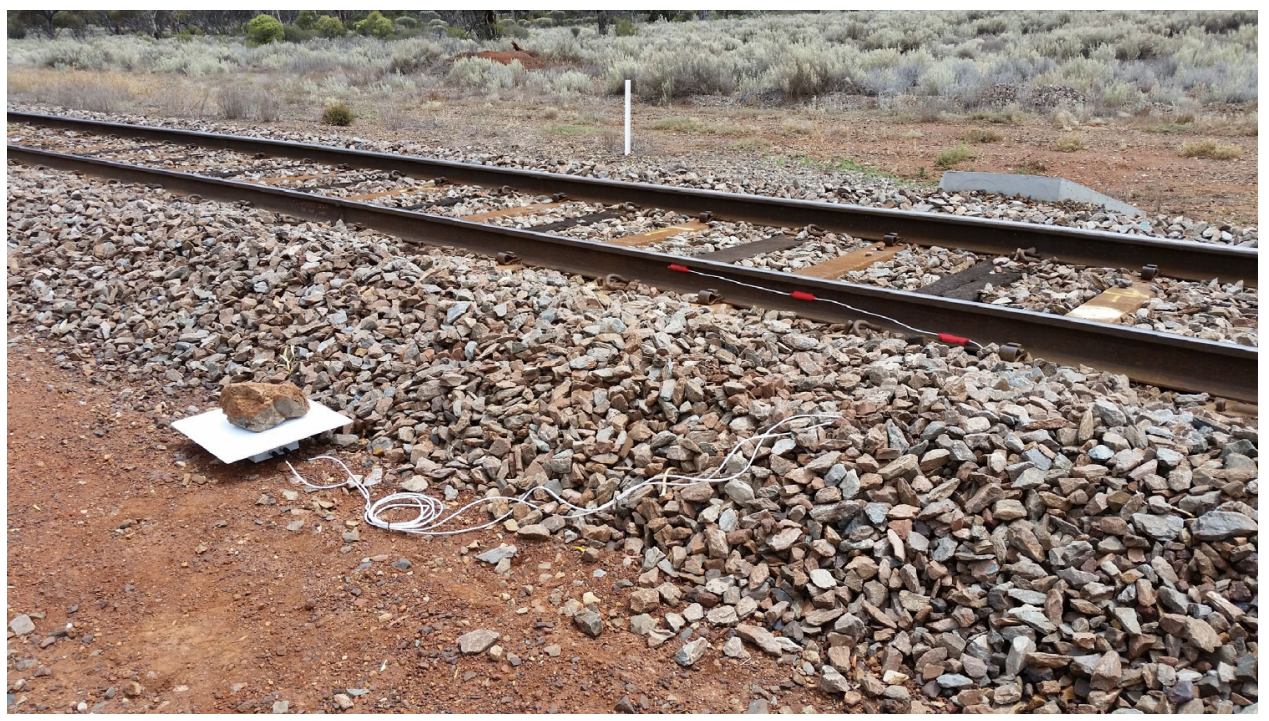

Fig. 7 Logger and temperature sensors installed in the field

operator to be approximate and could be roughly half hour different to the actual passage. The site 1 times provided were for a location approximately $30 \mathrm{~km}$ from the actual logger. The train passage times at site 1 for the analysis later described in this paper were derived based on average train speeds through that area. Site 2 and 3 locations are within $2 \mathrm{~km}$ of each other, with no signalling in between, so are therefore assumed as having the same approximate passage times. 


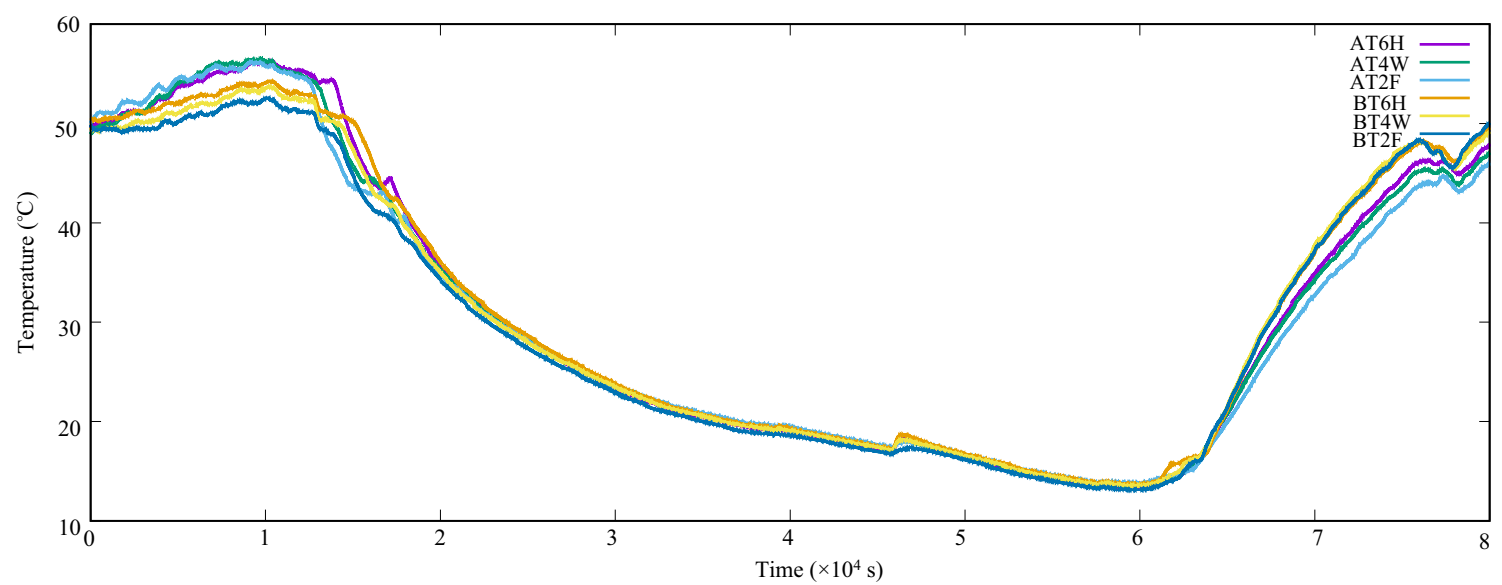

Fig. 8 Temperatures measured at site 2 using the field logger system

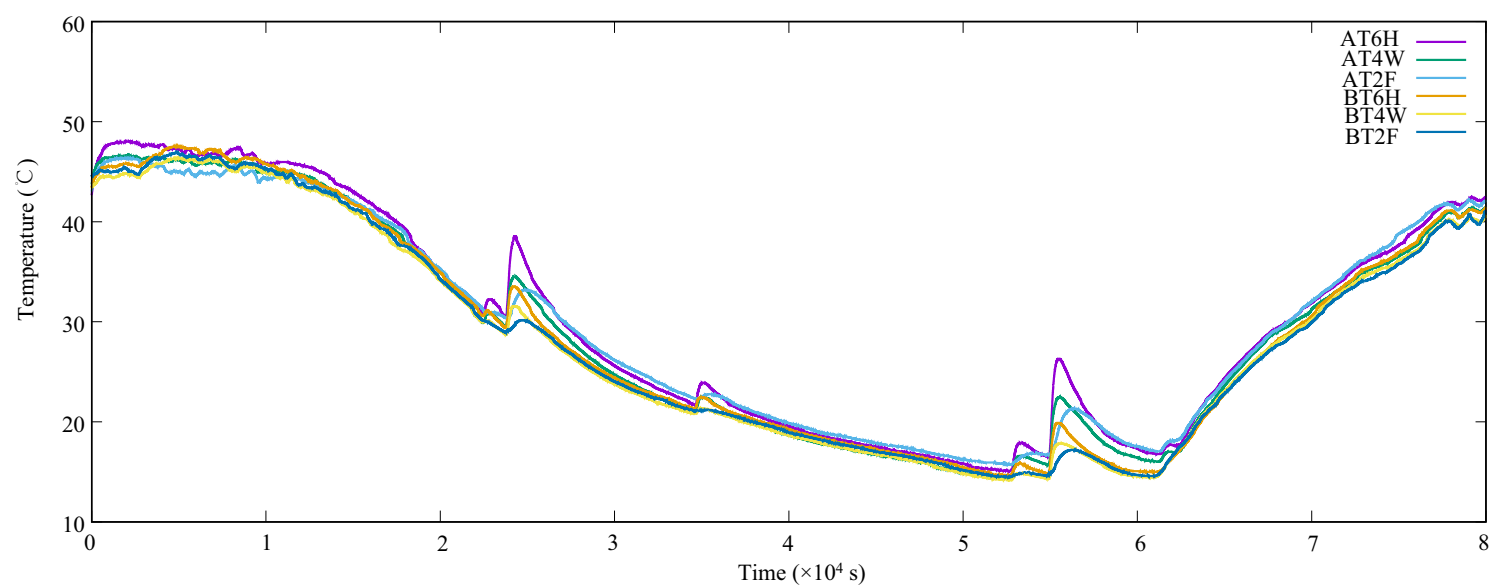

Fig. 9 Temperatures measured at site 5 using the field logger system

Table 6 Summary of logger installation performance for all five sites

\begin{tabular}{|c|c|c|c|c|}
\hline Site No. & Installation date & Total run-time (s) & Temperature string A & Temperature string B \\
\hline 1 & 2017-12-13 12:13 PM & 176,757 & High & Low \\
\hline 2 & 2017-12-13 10:50 AM & 180,034 & Tangent & Tangent \\
\hline 3 & 2017-12-13 09:57 AM & 182,837 & Low & High \\
\hline 4 & 2017-12-14 11:05 AM & 90,232 & High & Low \\
\hline 5 & 2017-12-14 12:30 PM & 80,827 & Low & High \\
\hline
\end{tabular}

The empty and loaded iron ore train in Table 5 followed the standard consist defined in Table 4, whilst the specific configuration of the fuel train was 2 locomotives, 31 wagons with a gross mass of $2663 \mathrm{t}$ and $607 \mathrm{~m}$ in length.

The results for the three trains with daily temperature fluctuation removed are shown in Figs. 10, 11 and 12.

\section{Discussion}

Before discussing foot temperatures, there are three key points identified for discussion from the temperature results presented, namely high rail vs low rail, changes in curve radius and the effect of traction. As each curve simulated in 

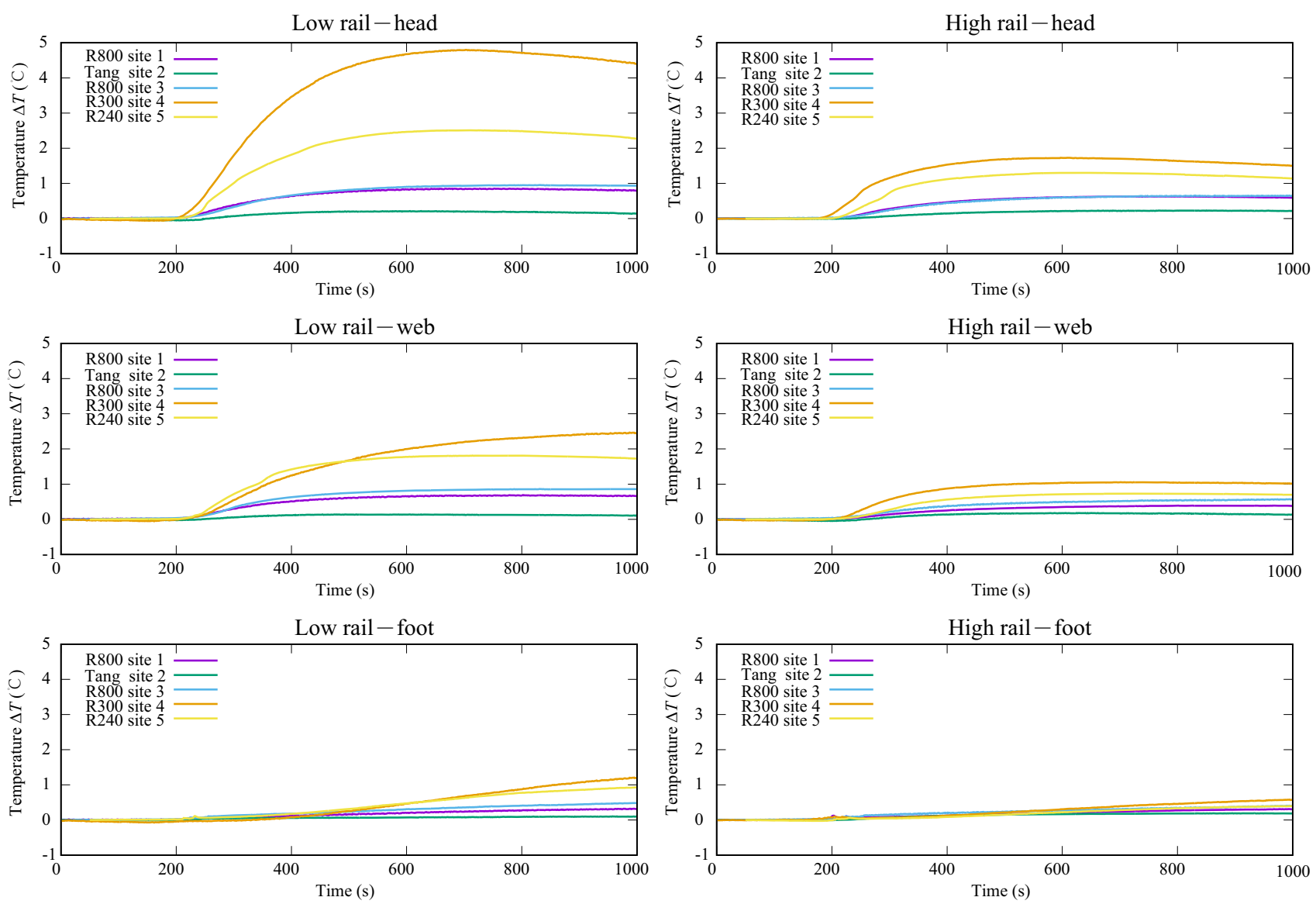

Fig. 10 Loaded fuel train operating from destination B to A

Table 3 has high lateral load, this variable is not considered in the discussion.

\subsection{High rail versus low rail}

Cant, or superelevation as it is also known, is the difference in height between the low (inside) rail and high (outside) rail on a curve. In freight operations it is common to allow trains to run through curves at speeds which are in excess of the equilibrium speed for the particular superelevation installed and this causes the vehicle wheels to exert a greater force on the outside rail. The result of this is that the high rail has considerable load on it.

Although cant deficiency is common, it is not always the case as in some instances external influences such as train performance may determine nominated running speeds for a track section that are significantly lower than cant deficient speeds for all the curves present. In this scenario there will be considerable load transferred to the low rail.

On a curve, the inside wheel of a fixed wheelset travels a shorter distance than the outer wheel and, in a cant deficient curve may lead to the inside wheel spinning. In the cant excess situation where the low leg is loaded there may be sufficient traction to cause the outer wheel to slide. The cant scenario in the case of the results presented is unknown as running speed was not recorded, however, it is clearly seen that the temperature of the low rail is greater than that of the high rail. The addition of speed measurement at each site would be beneficial in future work.

\subsection{Curve radius}

Continuing on from the point made in the previous section, as the curve radius increases, the difference in the distance travelled by the inner and outer wheel decreases, resulting in a decrease in the spin on the inside wheel [14]. As a general trend, the $800 \mathrm{~m}$ radius curves have less than half the temperature generated in the wheel/rail contact interface compared to the $240 \mathrm{~m}$ and $300 \mathrm{~m}$ radius curves. It is duly noted that the tight radius curve temperatures differ quite significantly and further discussion around this is presented in the next section. As curve radius approaches an infinite value for the tangent track, the temperatures in the rail are very nearly identical as expected. 

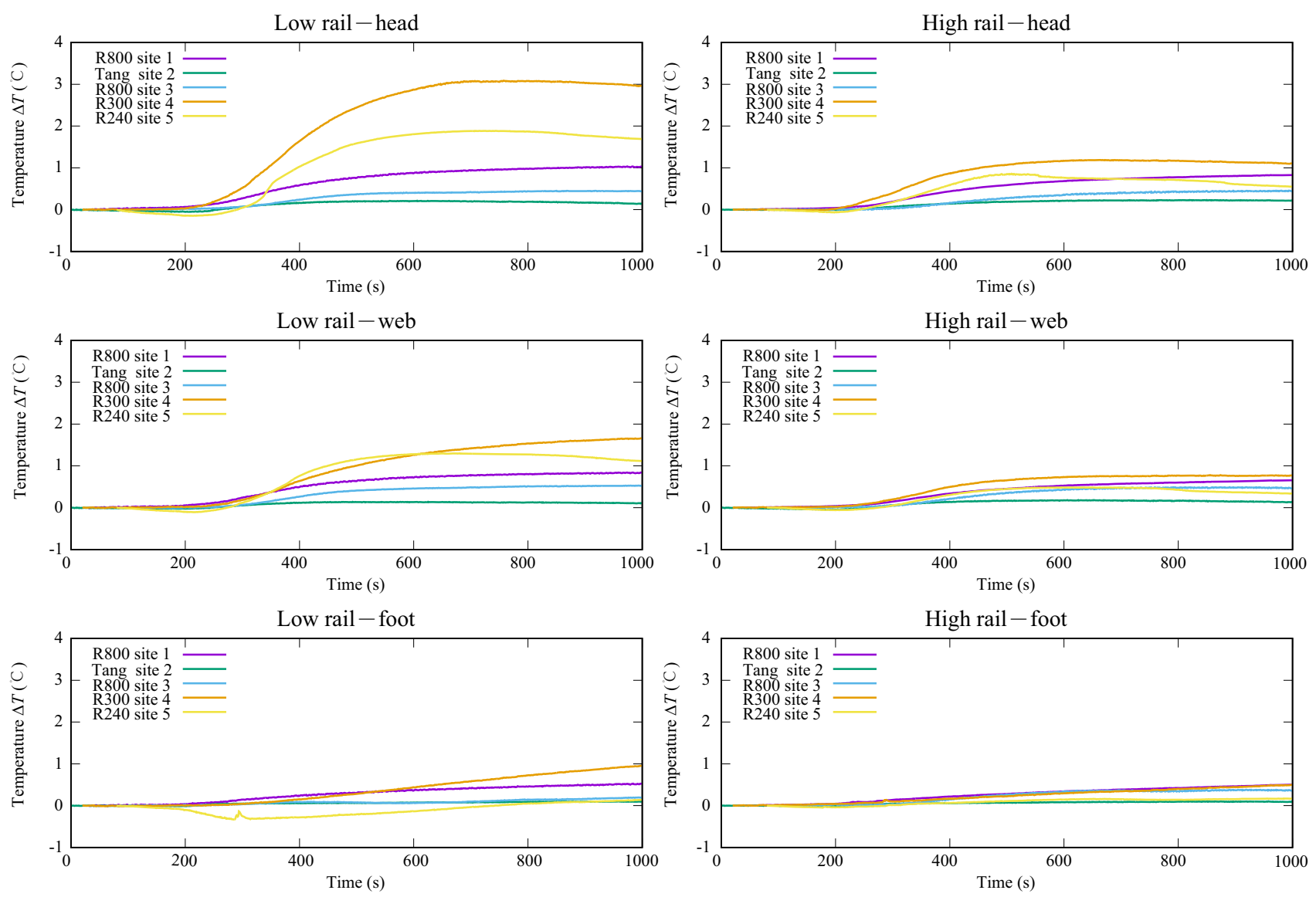

Fig. 11 Empty iron ore train operating from destination A to B

\subsection{Traction}

The results indicate that there is a temperature effect due to traction being exerted on the rail, specifically for the loaded fuel train case. The potential for traction to influence rail temperature is driven primarily by the locomotives in the train as they are the sole source of tractive effort. Therefore, any energy transfer must come through the wheel/rail contact interface by friction or conduction. It is also a function of speed; the greater the period the wheel is contacting a point, the greater the potential for energy transfer at that instant in time.

For the two loaded train cases presented in Figs. 10 and 12 , with power-to-weight ratios of 2.24 and $0.89 \mathrm{~kW} / \mathrm{t}$, respectively, it should be noted that these two trains are travelling loaded in different directions. Table 3 shows that the $240 \mathrm{~m}$ curve at site 5 is high traction for a loaded iron ore train. In nearly all cases in heavy haul train operations, instances of high traction are associated with grade. Therefore, in the case of the loaded fuel train, it is descending the grade at site 5 and more likely using dynamic brake or train. Site 4 is the reverse scenario, where there is a low traction situation for the loaded iron ore train and high traction scenario for the loaded fuel train.

The low rail head temperatures for the loaded fuel train show almost twice the temperature for the site 4 measurement compared to the site 5 measurement, indicating that traction is contributing to heating the rail. In the case of the loaded iron ore train, it is not as clear from the low rail head temperature that there has been a traction heating effect, however the low rail web shows an increased temperature indicating that there has been a higher energy transfer on average in the head of the rail. The grade descent at site 4 is also significant and requires a braking application. So, in the case of the loaded iron ore train at site 4 , while the traction requirement is low, the braking effect may be high. The higher energy transfer would correlate with a brake application as nearly all wheels in the train would be at higher temperatures as a result of brake shoe friction.

An analysis of the effect of traction in an empty train is difficult to quantify. In heavy haul networks the power to weight ratio for an empty train is quite high given they are generally about a $20 \%$ the weight of a loaded train. In this 
situation there is often very little requirement for high traction operation.

\subsection{Other heating effects}

There are two other sources of heat produced by rolling stock passage that have not been included in the discussion thus far and they are heating due to bending and sleeper/rail longitudinal rubbing. Laboratory experiments using a single wheel roller rig have shown that these two components only generate a 50 to $100 \mathrm{mK}$ change in rail temperature for 1000 bending cycles of $20 \mathrm{t}$ at rates between 1 to $10 \mathrm{~Hz}$. These magnitudes are inside the noise floor of the field measurements conducted and are therefore not considered.

\subsection{The foot}

The primary objective of the field measurement is to measure the heat transfer in the foot of the rail to determine if sufficient heat flux was present during the passage of a train such that it may be used as an active excitation source for a thermography-based technique for root foot flaw detection [15]. The goal of the project is to have the infrared imaging hardware installed on the train, so therefore the analysis of the rail foot temperatures should be constrained to the period where the train is passing over the flaw area.

The range of operating speeds on the network, excluding stoppages for signals is approximately 5 to $20 \mathrm{~m} / \mathrm{s}$. The iron ore trains on the network are the longest at over $2 \mathrm{~km}$ in length so therefore our passage time over any one point can vary between 100 to $400 \mathrm{~s}$. The train speed is unknown at each location so the analysis will assume a worst case of 400 s passage time.

It is clear from the set of graphs in Figs. 10, 11 and 12 that the heat transfer in the foot of the rail is dominated by conduction from the rail head. Using the $400 \mathrm{~s}$ passage time, the rail foot temperature increases by $1^{\circ} \mathrm{C}$ in the loaded iron ore train for both high and low rail on the tight radius curves and by only $0.5{ }^{\circ} \mathrm{C}$ for the empty iron ore train and loaded fuel train. For the larger curve radius and tangent track, the temperature increases are lower again
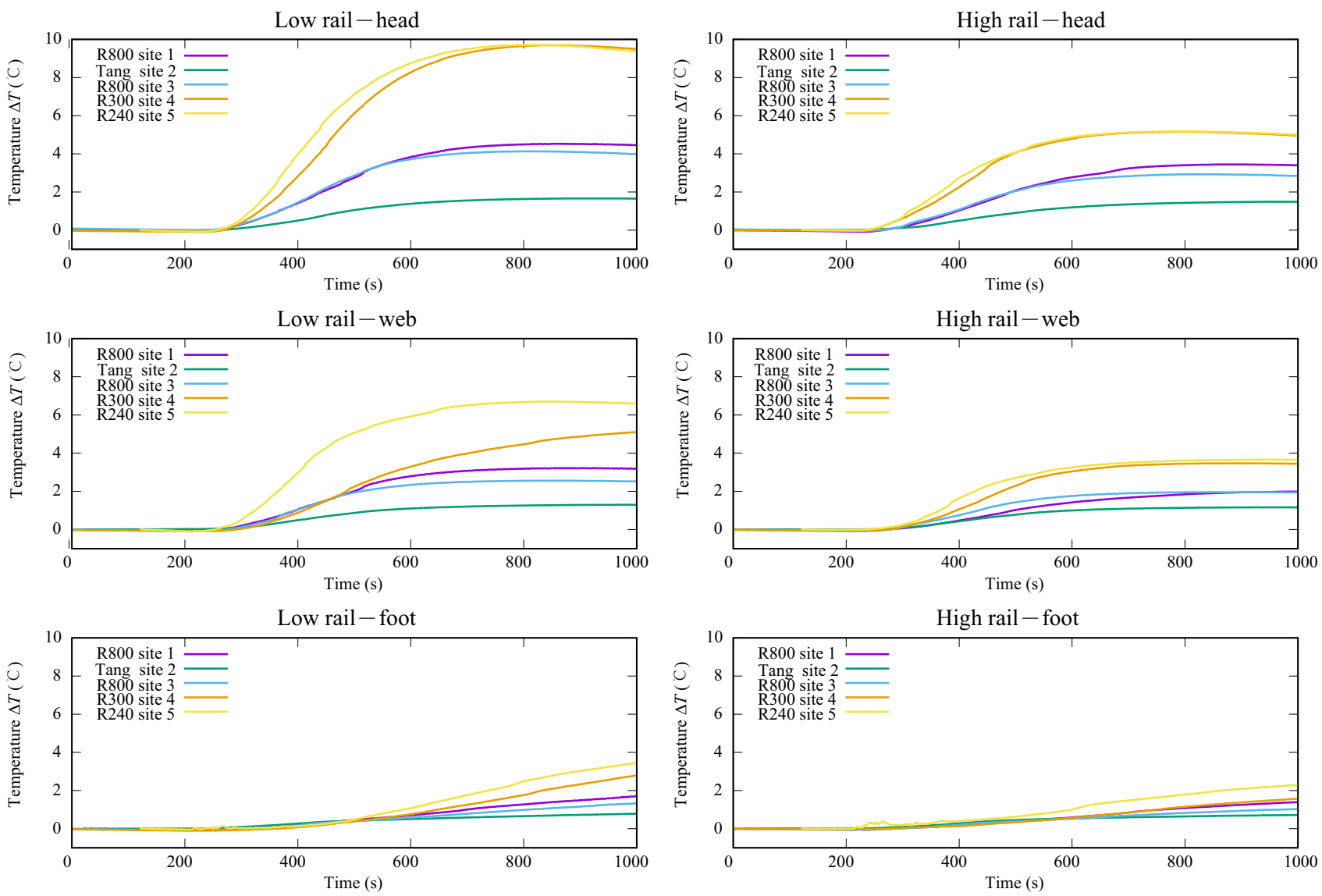

Fig. 12 Loaded iron ore travelling from destination A to B 
and are in the region of 0.1 to $0.3{ }^{\circ} \mathrm{C}$. It should be noted though that conduction from the rail head to the foot does continue to occur after the train has passed and the temperature increase exceeds $1{ }^{\circ} \mathrm{C}$ in all cases another $400 \mathrm{~s}$ later. The complete heating and cooling cycle have not been presented.

\section{Conclusion}

This paper has demonstrated a methodology for measuring the rail head, web and foot temperatures for both rails simultaneously in multiple locations. The loggers successfully recorded rail temperatures at five different sites selected for different combinations of traction and curve radius. A method was demonstrated for removing the cyclic ambient temperature induced rail temperature, leaving behind the resultant transient temperature due to train passage.

Analysis of these results indicated preliminary relationships between high and low rail temperature differentials and the influence of curve radius and traction. For deeper understanding of the processes at play further information on train handling is required. The paper concluded with a discussion on the resultant heat transfer in the foot of the rail, showing temperature increases in the foot in the range of 0.1 to $1{ }^{\circ} \mathrm{C}$ during train passage only. These results will inform the development and validation of a rail heat transfer model.

Acknowledgements The work was supported by the Australasian Centre for Rail Innovation under its HH01B-Evaluating infrared imaging and laser ultrasonics as detectors of rail foot flaws project.

Open Access This article is licensed under a Creative Commons Attribution 4.0 International License, which permits use, sharing, adaptation, distribution and reproduction in any medium or format, as long as you give appropriate credit to the original author(s) and the source, provide a link to the Creative Commons licence, and indicate if changes were made. The images or other third party material in this article are included in the article's Creative Commons licence, unless indicated otherwise in a credit line to the material. If material is not included in the article's Creative Commons licence and your intended use is not permitted by statutory regulation or exceeds the permitted use, you will need to obtain permission directly from the copyright holder. To view a copy of this licence, visit http://creativecommons. org/licenses/by/4.0/.

\section{References}

1. Hory C, Bouillaut L, Aknin P (2012) Time-frequency characterization of rail corrugation under a combined auto-regressive and matched filter scheme. Mech Syst Signal Process 29:174-186

2. Coccia S (2007) Ultrasonic guided waves for structural health monitoring and application to rail inspection prototype for the Federal Railroad Administration. Dissertation, University of California

3. ATSB. Investigation: RO-2014-014-Derailment of freight train 6DA2 near Marryat, SA on 26 July 2014. https://www.atsb.gov. au/publications/investigation_reports/2014/rair/ro-2014-014/. Accessed 9 Nov 2016

4. Office of the Chief Investigator. Derailment freight train Warracknabeal. http://economicdevelopment.vic.gov.au/_data/ assets/pdf_file/0009/1326933/2011-06-05-Freight-TrainDerailment-Warracknabeal.pdf. Accessed 5 Jan 2017

5. Mirković N, Brajović L, Popović Z et al (2021) Determination of temperature stresses in CWR based on measured rail surface temperatures. Constr Build Mater 284:122713

6. Crowe KE, Raj PK (1998) Analyses of rail chill effect. Federal Railroad Administration. Report No.: DOT-VNTSC-FRA-96-8

7. Zhu S, Luo J, Wang M, Cai C (2020) Mechanical characteristic variation of ballastless track in high-speed railway: effect of train-track interaction and environment loads. Railw Eng Sci 28(4):408-423

8. Texas Instruments. LM35 precision centigrade temperature sensors. http://www.ti.com/lit/ds/symlink/lm35.pdf

9. Delprete C, Rosso C (2009) An easy instrument and a methodology for the monitoring and the diagnosis of a rail. Mech Syst Signal Process 23(3):940-956

10. Galbreath JH, Townsend CR, Mundell SW et al. (2003) Civil structure strain monitoring with power-efficient, high-speed wireless sensor networks. In: 4th international workshop on structural health monitoring, Stanford University, Stanford CA, 15-17 Sept, 2003

11. Industries A. Adafruit feather M0 Adalogger. https://www. adafruit.com/product/2796. Accessed 18 April 2018

12. Kesler K, Zhang Y-J (2007) System and method for predicting future rail temperature. US20070265780 A1. http://www.google. com/patents/US20070265780. Accessed 8 Jan 2017

13. Wang S, Cai G, Zhu Z, Huang W, Zhang X (2015) Transient signal analysis based on Levenberg-Marquardt method for fault feature extraction of rotating machines. Mech Syst Signal Process 54-55:16-40

14. Bosomworth C, Spiryagin M, Alahakoon S, Cole C (2017) The effect of vehicle dynamics on rail foot flaw detection. In: Proceedings of the 25th International Symposium on Dynamics of Vehicles on Roads and Tracks (IAVSD 2017), 14-18 August 2017, Rockhampton. CRC Press, London

15. Bosomworth C, Sun YQ, Spiryagin M, Alahakoon S, Cole C (2017) Experimental Investigation into the use of thermography for the detection of rail foot flaws. In: First International Conference on Rail Transportation, Chengdu, pp 311-322 